\title{
Real-time detection of Mycoplasma pneumoniae in respiratory samples with an internal processing control
}

\author{
David Pitcher, Victoria J. Chalker, Carmen Sheppard, Robert C. George \\ and Timothy G. Harrison
}

Correspondence

Victoria J. Chalker

vicki.chalker@hpa.org.uk

Received 4 August 2005

Accepted 16 September 2005
Respiratory and Systemic Infection Laboratory, Health Protection Agency Centre for Infections, 61 Colindale Avenue, London NW9 5EQ, UK

Real-time PCR was employed to detect a region of the P1 cytadhesin gene of Mycoplasma pneumoniae in clinical samples. An internal processing control was included that could be co-amplified simultaneously in the same reaction tube. The assay could reproducibly detect $1 \times 10^{3} \mathrm{M}$. pneumoniae organisms $\mathrm{ml}^{-1}$ in clinical samples. There was no amplification of DNA or signal production from 15 other species of human mycoplasmas and 19 other bacterial species. Using a panel of 175 respiratory samples taken from patients with pneumonia of proven aetiology, the sensitivity was found to be $60 \%$ and the specificity of the assay $96 \cdot 7 \%$ when compared with serology. This assay is suitable for same-day diagnosis of $M$. pneumoniae infection and batch processing of respiratory samples for clinical screening.

\section{INTRODUCTION}

Mycoplasma pneumoniae is a common cause of communityacquired pneumonia transmitted by aerosol or close contact (Friedlaender et al., 1976). Major outbreaks occur periodically and the severity of clinical symptoms ranges from asymptomatic to pronounced pneumonia (Clyde, 1993). A wide variety of extrapulmonary manifestations have been reported such as haematological, gastrointestinal, musculoskeletal, dermatological and neurological complications (McMillan, 1998). Traditionally, serological methods for detecting specific IgM, IgG and IgA have been used to establish diagnosis of infection. However, detectable levels of antibodies may not be attained until 7-10 days after the onset of symptoms (Sillis, 1993; McMillan, 1998). Culture requires specialized media, is time-consuming (up to 21 days) and is rarely undertaken in a routine context.

Due to the vast reduction in time in comparison with culture, PCR has been used increasingly for M. pneumoniae detection. Several gene targets have been used for amplification, including the $16 \mathrm{~S}$ rRNA gene, the elongation factor tuf, the P1 cytadhesin gene and repetitive elements located within the latter (Razin, 1994; Ursi et al., 2003; Michelow et al., 2004; Miyashita et al., 2004; Nour et al., 2005). The P1 cytadhesin gene encodes the $169 \mathrm{kDa} \mathrm{P} 1$ protein of M. pneumoniae. This protein is the major virulence and adhesin factor of $M$. pneumoniae and is located at the

Abbreviations: Cp, crossing point; IPC, internal processing control.

The sequence of the internal processing control bacteriophage lambda fragment is available as supplementary material in JMM Online. terminal attachment organelle, wherein it attaches to host cells (Svenstrup et al., 2002). Although similar genes are found in some other mycoplasma species, highly conserved regions of the sequence are unique to $M$. pneumoniae and this gene is therefore an attractive target for the design of species-specific PCR primers (Su et al., 1987). The use of the Roche LightCycler with fluorescence resonance energy transfer hybridization probes has been applied to the detection of several bacterial pathogens including Chlamydia pneumoniae (Mygind et al., 2001), Neisseria gonorrhoeae (Whiley et al., 2002), Bordetella spp. (Cloud et al., 2003) and M. pneumoniae (Ursi et al., 2003). Multiplex assays have also been described that enable the simultaneous detection of M. pneumoniae with other pathogens (Khanna et al., 2005; Raggam et al., 2005; Stralin et al., 2005). The purpose of this study was to establish a reliable, specific, sensitive and quantitative real-time PCR to detect M. pneumoniae in clinical specimens and to improve the current clinical diagnostic service. An internal processing control (IPC) was included to highlight amplification failure of the reaction due to inhibition.

\section{METHODS}

Clinical samples. A panel of 167 clinical respiratory samples (sputa and bronchoscopy specimens, group A), urine and acute and convalescent serum samples were taken on admission to hospital in 19911992 as part of a prospective clinical trial. Patients were excluded from the study if they were undergoing antibiotic therapy immediately prior to presentation at hospital. Samples were taken from adult patients (mean age 46 years, $\mathrm{SD} \pm 19 \cdot 6$, $95 \%$ CI $41 \cdot 4-51 \cdot 4$, range 18-80) with radiologically confirmed acute communityacquired pneumonia and those of proven aetiology were made 
available for retrospective examination in this study. Clinical samples from the patients had previously been examined immediately after collection for evidence of a range of respiratory pathogens by standard culture or serological methods as shown in Table 1. An additional eight sputum specimens (group B) from patients with pneumonia that had been serologically confirmed as $M$. pneumoniae positive were included in the study; four of these samples were also confirmed as positive for M. pneumoniae by culture. Samples were then frozen at $-80{ }^{\circ} \mathrm{C}$ and later tested for Legionella and other atypical pathogens, including serological testing for M. pneumoniae IgG and IgM antibodies by indirect immunofluorescence (Wreghitt \& Sillis, 1985). After several years, respiratory samples were thawed, treated with Sputasol (Oxoid) for $30 \mathrm{~min}$ at room temperature, heated for $10 \mathrm{~min}$ at $65^{\circ} \mathrm{C}$ and heated for $15 \mathrm{~min}$ at $100{ }^{\circ} \mathrm{C}$ to ensure inactivation of any tubercle bacilli or other pathogens. DNA was then extracted from $200 \mu \mathrm{l}$ of each respiratory sample using the QIAamp DNA Mini kit (Qiagen). The eluted samples (200 $\mu \mathrm{l})$ were tested immediately for M. pneumoniae DNA.

Reference strains. The following reference strains were included in this study. Mollicute species: Acholeplasma laidlawii NCTC $10116^{\mathrm{T}}$, Mycoplasma amphoriforme NCTC $11740^{\mathrm{T}}$, Mycoplasma buccale NCTC $10136^{\mathrm{T}}$, Mycoplasma faucium NCTC $10174^{\mathrm{T}}$, Mycoplasma fermentans NCTC $10117^{\mathrm{T}}$, Mycoplasma genitalium NCTC $10195^{\mathrm{T}}$, Mycoplasma

Table 1. M. pneumoniae LightCycler PCR results on respiratory samples from adults with pneumonia of proven aetiology

Evidence for aetiology: Chlamydophila spp., Coxiella burnetii, RSV, influenza A and influenza B by complement-fixation test; Streptococcus pneumoniae cultured from blood, bronchoscopy samples, sputum or antigen in urine; Enterobacteriaceae, $\beta$-haemolytic streptococci, H. influenzae, Moraxella catarrhalis and Staphylococcus aureus cultured from bronchoscopy samples or sputum; L. pneumophila antigen in urine or serology. Sputum isolates were considered causative if $\geqslant 10^{6}$ c.f.u. $\mathrm{ml}^{-1}$ (Streptococcus pneumoniae) or $\geqslant 10^{7}$ c.f.u. $\mathrm{ml}^{-1}$ (other organisms) were detected with $\geqslant 25$ polymorphonuclear cells $\mathrm{ml}^{-1}$. $M$. pneumoniae-positive samples were determined by immunofluorescence.

\begin{tabular}{|c|c|}
\hline Causative organism & PCR positive/total (\%) \\
\hline Group A & $16 / 167(9 \cdot 6)$ \\
\hline Single infections & $5 / 132$ \\
\hline Chlamydophila spp. & $1 / 9$ \\
\hline Coxiella burnetii & $0 / 1$ \\
\hline Enterobacteriaceae & $0 / 2$ \\
\hline$\beta$-Haemolytic streptococci & $0 / 3$ \\
\hline Haemophilus influenzae & $1 / 33$ \\
\hline Influenza A virus & $0 / 1$ \\
\hline Influenza B virus & $0 / 2$ \\
\hline Legionella pneumophila & $0 / 4$ \\
\hline Moraxella catarrhalis & $0 / 2$ \\
\hline Respiratory syncytial virus (RSV) & $0 / 2$ \\
\hline Staphylococcus aureus & $0 / 3$ \\
\hline Streptococcus pneumoniae & $3 / 70$ \\
\hline Mixed infections & $0 / 18$ \\
\hline Coxiella burnetii and $\beta$-haemolytic streptococci & $0 / 1$ \\
\hline H. influenzae and Moraxella catarrhalis & $0 / 1$ \\
\hline Staphylococcus aureus and influenza B virus & $0 / 1$ \\
\hline Streptococcus pneumoniae and Chlamydophila spp. & $0 / 1$ \\
\hline Streptococcus pneumoniae and $H$. influenzae & $0 / 8$ \\
\hline Streptococcus pneumoniae and influenza B virus & $0 / 2$ \\
\hline Streptococcus pneumoniae and Moraxella catarrhalis & $0 / 3$ \\
\hline Streptococcus pneumoniae and RSV & $0 / 1$ \\
\hline M. pneumoniae confirmed & $11 / 17$ \\
\hline M. pneumoniae & $10 / 15$ \\
\hline M. pneumoniae and $\beta$-haemolytic streptococci & $1 / 1$ \\
\hline M. pneumoniae and RSV & $0 / 1$ \\
\hline Group B & $4 / 8(50 \cdot 0)$ \\
\hline M. pneumoniae serology-positive, culture-negative & $0 / 4$ \\
\hline M. pneumoniae serology-positive, culture-positive & $4 / 4$ \\
\hline Total PCR positive (Group A + B) & $20 / 175(11 \cdot 4)$ \\
\hline Total PCR positive, serology-positive & $15 / 25(60 \cdot 0)$ \\
\hline Total PCR positive, serology-negative & $5 / 150(3 \cdot 3)$ \\
\hline
\end{tabular}


hominis NCTC $10111^{\mathrm{T}}$, Mycoplasma lipophilum NCTC $10173^{\mathrm{T}}$, Mycoplasma orale NCTC $10112^{\mathrm{T}}$, Mycoplasma penetrans ATCC $55252^{\mathrm{T}}$, Mycoplasma pirum NCTC $11702^{\mathrm{T}}$, M. pneumoniae NCTC $10119^{\mathrm{T}}$, Mycoplasma salivarium NCTC $10113^{\mathrm{T}}$, Mycoplasma spermatophilum NCTC $11720^{\mathrm{T}}$, Ureaplasma parvum ATCC 33697, Ureaplasma urealyticum NCTC $10177^{\mathrm{T}}$. Respiratory species: Actinomyces odontolyticus NCTC $9935^{\mathrm{T}}$, Bordetella parapertussis NCTC $5952^{\mathrm{T}}$, Bordetella pertussis NCTC $10739^{\mathrm{T}}$, Burkholderia cepacia NCTC 10743, Chlamydophila pneumoniae IOL-207, Chlamydophila psittaci $6 \mathrm{BC}^{\mathrm{T}}$, Corynebacterium diphtheriae NCTC 10356, Enterococcus faecalis NCTC $775^{\mathrm{T}}$, Escherichia coli NCTC $9001^{\mathrm{T}}$, Haemophilus influenzae NCTC $8143^{\mathrm{T}}$, Klebsiella pneumoniae subsp. pneumoniae NCTC $9633^{\mathrm{T}}$, Legionella pneumophila NCTC $11192^{\mathrm{T}}$, Moraxella catarrhalis NCTC $11020^{\mathrm{T}}$, Pseudomonas aeruginosa NCTC $10332^{\mathrm{T}}$, Rothia dentocariosa NCTC $10917^{\mathrm{T}}$, Staphylococcus aureus NCTC $8532^{\mathrm{T}}$, group G streptococcus NCTC 9603, Streptococcus pneumoniae NCTC $7465^{\mathrm{T}}$, Streptococcus pyogenes NCTC 12067.

Extraction of DNA from bacterial cultures. Cultures of mollicute species, A. odontolyticus and $R$. dentocariosa $(5 \mathrm{ml})$ were concentrated by centrifugation at $8000 \mathrm{~g}$ for $15 \mathrm{~min}$, resuspended in $180 \mu \mathrm{l}$ nuclease-free water and extracted with $20 \mu \mathrm{l}$ Instagene matrix (Bio-Rad) according to the manufacturer's instructions. All other strains used in the specificity panel were extracted by using the Roche MagNAPure robot using the DNA isolation kit III (Roche Diagnostics) according to the manufacturer's instructions. DNA concentration was adjusted to approximately $20 \mathrm{pg}^{-1}$ for use in the LightCycler assay.

Primers and probes. The sequences of all primers and probes are listed in Table 2. Primers specific for the RepMP2 repetitive element (GenBank accession no. X13087) of the P1 cytadhesin gene of M. pneumoniae were designed using the primer selection program OLIGO (Medprobe) to amplify a PCR product of $141 \mathrm{bp}$. Within this sequence, two probes were designed to a $43 \mathrm{bp}$ region with a $2 \mathrm{bp}$ gap located proximal to the $3^{\prime}$ end of the sense sequence.

Construction of a PCR IPC. A 278 bp sequence from $\lambda$ phage DNA into which $M$. pneumoniae primer sites were incorporated was amplified using primer sequences for M. pneumoniae with $\lambda$ phage amplifying sequences at their $3^{\prime}$ ends (Table 2; full sequence available as supplementary material in JMM Online). $\lambda$ DNA $(1 \mu \mathrm{g}$; Sigma) was digested with EcoRI for 3 h. The restricted DNA (10 ng) was used as a template in a $50 \mu \mathrm{l}$ PCR containing $150 \mathrm{mM} \mathrm{NaCl}$, $1.5 \mathrm{mM} \mathrm{MgCl} 2,10 \mathrm{mM}$ Tris/HCl ( $\mathrm{pH} \mathrm{8} \cdot 0), 1 \mathrm{U}$ Taq DNA polymerase (Gibco-BRL), $10 \mathrm{pM}$ each of primers M-IPC-1 and M-IPC2, and $200 \mu \mathrm{M}$ deoxyribonucleotides. PCR was performed on a
Peltier Thermal Cycler (225) DNA Engine Tetrad and reaction conditions were 30 cycles of $95^{\circ} \mathrm{C}$ for $30 \mathrm{~s}, 40{ }^{\circ} \mathrm{C}$ for $1 \mathrm{~min}$ and $72{ }^{\circ} \mathrm{C}$ for $1 \mathrm{~min}$, with a final extension step at $72^{\circ} \mathrm{C}$ for $10 \mathrm{~min}$. The product size was confirmed by electrophoresis and the concentration of the product was estimated using a GeneQuant spectrophotometer (Pharmacia). The product was then cloned into the pCR2.1TOPO plasmid using the TOPO TA cloning kit (Invitrogen), transformed into Escherichia coli $\mathrm{INV} \alpha \mathrm{F}^{\prime}$ and positive transformants were selected according to the manufacturer's instructions. Positive transformants were cultured overnight in Luria-Bertani broth $(5 \mathrm{ml})$ containing $50 \mu \mathrm{g}$ ampicillin $\mathrm{ml}^{-1}$ and plasmid DNA was extracted using a Plas-

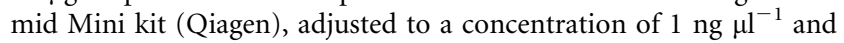
then heated at $95^{\circ} \mathrm{C}$ for $5 \mathrm{~min}$. Plasmid preparations with inserts of the expected size (278 bp) were confirmed by PCR selection as follows. PCR reagents were as above with the inclusion of primers Mpn-3 and Mpn-4 (Table 2) and reaction conditions were 30 cycles of $95^{\circ} \mathrm{C}$ for $30 \mathrm{~s}, 58^{\circ} \mathrm{C}$ for $30 \mathrm{~s}$ and $72^{\circ} \mathrm{C}$ for $1 \mathrm{~min}$, with a final extension step at $72{ }^{\circ} \mathrm{C}$ for $10 \mathrm{~min}$. The resulting IPC plasmid was linearized by digestion with $X b a \mathrm{I}$, adjusted to $10^{10}$ copies $\mu \mathrm{l}^{-1}$ in TE buffer [10 mM Tris/HCl ( $\mathrm{pH} 8 \cdot 0), 1 \mathrm{mM}$ EDTA] containing herring sperm DNA (10 ng $\mu \mathrm{l}^{-1}$; Gibco-BRL) and stored as $35 \mu \mathrm{l}$ aliquots at $-80^{\circ} \mathrm{C}$. For use in the assay, stocks of IPC were diluted to $10^{2}$ copies $\mu^{-1}$ in nuclease-free water.

Construction of a M. pneumoniae PCR positive control. To alleviate problems associated with growing large volumes of $M$. pneumoniae to generate stocks of standard DNA, a cloned template DNA sequence was prepared for use as a positive control. A $410 \mathrm{bp}$ PCR product of the P1 cytadhesin gene, external to the amplicon in the LightCycler assay, was amplified using primers Mpn-1 and Mpn-2 (Table 2) from M. pneumoniae strain FH (NCTC $10119^{\mathrm{T}}$ ). This product was cloned and prepared as above and a stock solution containing $10^{10}$ copies $\mu \mathrm{l}^{-1}$ was prepared in TE buffer containing herring sperm DNA $\left(10 \mathrm{ng} \mu^{-1}\right)$. The stock solution was serially diluted in nuclease-free water to give a concentration range that covered the expected dynamic range of the clinical specimens. Each LightCycler run included positive-control samples with $10^{4}$, $10^{3}, 10^{2}$ and $10^{1}$ copies per PCR and a negative control (nucleasefree water). To assess reproducibility and stability, the crossingpoint $(\mathrm{Cp})$ values of these standards were monitored over several months.

LightCycler assay. Assays were carried out using a LightCycler (Roche) and the $\mathrm{MgCl}_{2}$ concentration was optimized according to the manufacturer's instructions. Reaction volumes $(20 \mu \mathrm{l}$ in total $)$ in glass capillary tubes (Roche) were used containing $2 \mu \mathrm{l}$ of LightCycler FastStart DNA Master Hybridization Probes (which includes

Table 2. Primers and probes

\begin{tabular}{|lll|}
\hline Primers and purpose & Name & Sequence $\left(\mathbf{5}^{\prime} \rightarrow \mathbf{3}^{\prime}\right)$ \\
\hline Cloning standard, forward & Mpn-1 & AGGGGGTTCCTTCAGGCTCAG \\
Cloning standard, reverse & Mpn-2 & GGATCAAACAGATCGGTGACTGGGT \\
Cloning internal processing control (IPC), forward ${ }^{*}$ & M-IPC-1 & TCTTCAGGCTCAGGTCAAatgcgtaagcgaaaca \\
Cloning IPC, reverse & M-IPC-2 & TTCCCCGTATTAGTATTAGGCgcataaacgaagcagtcgagt \\
LightCycler assay, forward & Mpn-3 & TCTTCAGGCTCAGGTCAA \\
LightCycler assay, reverse & Mpn-4 & TTCCCCGTATTAGTATTAGGC \\
Donor probe for $M$. pneumoniae & Mpn-DN & CAGTTACCAAGCACGAGTGAC-(FITC) \\
Acceptor probe for $M$. pneumoniae & Mpn-AC & (Red 640)-AAACACCTCCTCCACCAACA-(PO $\left.{ }_{4}\right)$ \\
Donor probe for IPC & IPC-DN & GGTGCCGTTCACTTCACTTCCCGAATAAC-(FITC) \\
Acceptor probe for IPC & IPC-AC & (Red 705)-GATATTTTTGATCTGACCGAAGCGC-(PO $\left.{ }_{4}\right)$ \\
\hline
\end{tabular}

${ }^{\star}$ IPC: M. pneumoniae primer sequence in upper case, $\lambda$ primer sequence in lower case. 
reaction buffer, nucleotides and Taq polymerase; Roche), $1.0 \mu \mathrm{M}$ Mpn-3 and Mpn-4 primers (Table 2), $5 \mathrm{mM} \mathrm{MgCl}_{2}, 0 \cdot 25 \mu \mathrm{M}$ each of the probes Mpn-DN, Mpn-AC, IPC-DN and IPC-AC (Table 2), $10^{2}$ copies of the IPC, $1 \mathrm{U}$ uracil-DNA glycosylase (Roche) and $5 \mu \mathrm{l}$ sample or positive/negative control. LightCycler FastStart DNA Master Hybridization Probes (Roche) reagent contains dUTP (not dTTP), and uracil-DNA glycosylase (Roche) was added to each reaction to eliminate carry-over contamination (Longo et al., 1990). Capillaries were sealed and placed in the LightCycler and the following cycling conditions applied: initial denaturation at $96^{\circ} \mathrm{C}$ for $10 \mathrm{~min}$ (transition rate $20^{\circ} \mathrm{C} \mathrm{s}^{-1}$; acquisition mode none); 45 quantification cycles of $95^{\circ} \mathrm{C}$ for $10 \mathrm{~s}$ (transition rate $20^{\circ} \mathrm{C} \mathrm{s}^{-1}$; acquisition mode none), $62{ }^{\circ} \mathrm{C}$ for $10 \mathrm{~s}$ (transition rate $20^{\circ} \mathrm{C} \mathrm{s}^{-1}$; acquisition mode single) and $74{ }^{\circ} \mathrm{C}$ for $15 \mathrm{~s}$ (transition rate $3{ }^{\circ} \mathrm{C} \mathrm{s}^{-1}$; acquisition mode none); melting curve cycle of $95^{\circ} \mathrm{C}$ for $0 \mathrm{~s}$ (transition rate $20^{\circ} \mathrm{C} \mathrm{s}^{-1}$; acquisition mode none), $45^{\circ} \mathrm{C}$ for $2 \mathrm{~s}$ (transition rate $20^{\circ} \mathrm{C} \mathrm{s}^{-1}$; acquisition mode none) and $85^{\circ} \mathrm{C}$ for $0 \mathrm{~s}$ (transition rate $0.1{ }^{\circ} \mathrm{C} \mathrm{s}{ }^{-1}$; acquisition mode cont); cooling at $40{ }^{\circ} \mathrm{C}$ for $30 \mathrm{~s}$ (transition rate $0{ }^{\circ} \mathrm{C} \mathrm{s}^{-1}$; acquisition mode none).

Data were analysed using Roche LightCycler software version 3.5 using arithmetic baseline adjustment and second-derivative maximum analysis (Fig. 1). Copy number was estimated from the Cp threshold relative to positive standards; samples that did not give a positive result and in which the IPC did not amplify were recorded as inhibitory and were repeated undiluted and diluted 1/10 in nuclease-free water (Promega).

\section{RESULTS AND DISCUSSION}

The use of real-time PCR was employed to detect $M$. pneumoniae in clinical samples using a Roche LightCycler. In total, $30 / 175(17 \cdot 1 \%)$ samples were positive by PCR, culture or serology. This figure could not be linked to prevalence or carriage in the population, as all patients had clinical signs of pneumonia and control samples from healthy patients were not available for study.

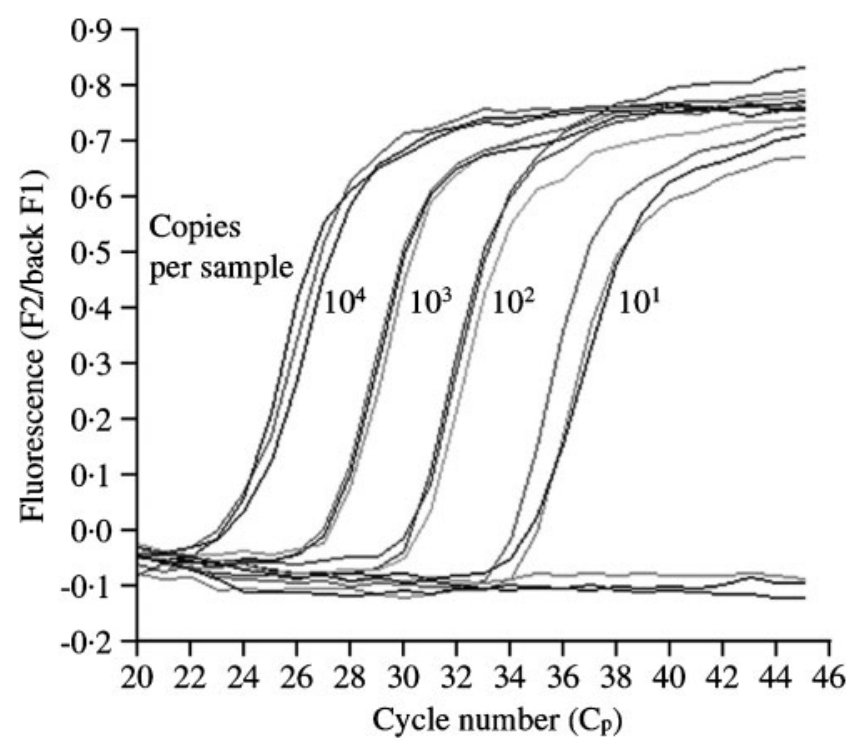

Fig. 1. Replicate standards of $M$. pneumoniae cloned DNA from $10^{1}$ to $10^{4}$ copies per sample. Channel F2, Red 640 fluorescence.

\section{Sensitivity}

The assay detected 10 copies or more of the target sequence in the $5 \mu \mathrm{l}$ samples used in the assay [corresponding to $2 \cdot 0 \times 10^{3}$ organisms $(\mathrm{ml} \text { extracted concentrated DNA })^{-1}$ and $1 \times 10^{3}$ organisms ( $\mathrm{ml}$ actual clinical sample $\left.)^{-1}\right]$. The estimated copy number in actual clinical samples from proven $M$. pneumoniae patients ranged from $5 \cdot 0 \times 10^{3}$ to $6.5 \times 10^{7}$ organisms $\mathrm{ml}^{-1}$. Samples with a $\mathrm{Cp}$ equal to or less than the lowest standard in the assay were deemed negative. Due to the absence of control specimens from healthy individuals, this study could not ascertain the level of $M$. pneumoniae in subclinical colonization and the use of the method in population screening is therefore limited. The LightCycler is capable of measuring the genome load in clinical specimens accurately, yet in practice, it is of little use in applying quantitative analyses to bacterial numbers in the respiratory tract, as specimens vary considerably in volume, consistency and composition and contain substances inhibitory to PCR. The measurement of an estimated bacterial load in this case can only be considered as semi-quantitative, and without a case-control study examining $M$. pneumoniae load in clinical specimens from both healthy and pneumonic specimens over the infective period little clinical relevance can be drawn other than the presence or absence of detectable M. pneumoniae DNA. None the less, of the 175 pneumonic patient samples tested, $20(11 \cdot 4 \%)$ were positive in the real-time assay (Table 1). In 25 of 175 patients, a diagnosis of $M$. pneumoniae infection had been previously established by serology, of which $15 / 25(60 \cdot 0 \%)$ were positive by this real-time method (groups A and B): four had also previously been confirmed by culture (group B). Four samples were serologically positive, yet negative by culture and PCR (group B). This may be due to cross-reactive antibody tests, increased sensitivity of antibody detection methods in comparison with PCR and culture, clearance of the micro-organism from the body or early treatment with antibiotics. The latter is unlikely as patients receiving antibiotic therapy were excluded from the study. It is possible that a period occurs during the infection process that is optimal for the detection of M. pneumoniae by PCR. Specimens were taken on admission to hospital, which corresponded to between 0 and 17 days after the onset of clinical signs. Those found to be positive by PCR in group A were taken on average 7 days after onset (2-17 days, $\mathrm{SD} \pm 4 \cdot 48)$ of symptoms, in comparison with PCR-negative samples taken 3 days post-onset $(0-12$ days, $\mathrm{SD} \pm 2 \cdot 36)$.

The sensitivity was estimated at $60.0 \%$ in comparison with serological positives obtained from paired acute and convalescent serum samples. Paired serum samples are not often received by clinical laboratories and comparison of the PCR assay with serology on single serum samples may have reflected use in practice more accurately. This level of sensitivity may be considered low; however, reports from other publications and the basis for calculating sensitivity have varied considerably. Michelow et al. (2004) reported a respiratory-sample PCR with a sensitivity of $57 \%$ and specificity of $98 \%$ when compared with $M$. pneumoniae 
ELISA. Hardegger et al. (2000) reported a P1 gene TaqMan real-time assay to detect $M$. pneumoniae that could detect a $1: 100$ dilution of a DNA sample. However, no indication of DNA concentration or target copy number in positivecontrol samples was given and it is not possible to make a direct comparison of sensitivity between this and other methods. Miyashita et al. (2004) noted that their multiplex assay could detect 100 copies $\mathrm{ml}^{-1}$, and Dorigo-Zetsma et al. (1999) reported an estimated sensitivity of $78 \%$ in a blockbased PCR. Using a similar assay to that described in this study, Ursi et al. (2003) noted a sensitivity of $5 \times 10^{3}-5 \times 10^{4}$ organisms $\mathrm{ml}^{-1}$, indicating that the assay described here is 5-50 times more sensitive. Our assay could be improved further by the addition of a second M. pneumoniae target, allowing confirmation of positive results simultaneously with detection. Sensitivity can be dependent on several factors, such as the method used for comparison and selection criteria for evidence of infection (PCR, culture or sero-conversion as the 'gold standard'), the presence of competitive DNA and inhibitors, sample type (swab, aspirate, sputum), method, age, transport and storage, operator variance, sample dilution and the method of extraction. Ievens et al. (1996) compared the PCR sensitivities of a simple boiling/freezing extraction and a guanidium thiocyanate/phenol extraction in two separate laboratories and found that results varied considerably between techniques and laboratories. This retrospective study utilized archived samples that had been stored at $-80^{\circ} \mathrm{C}$ for several years and had been heat-treated; therefore deterioration in the quality of the DNA in the samples could have occurred. Furthermore, immunofluorescence for M. pneumoniae antibody detection is highly subjective and, due to the lack of standardization across the techniques, caution should be employed when comparing techniques for M. pneumoniae detection (Loens et al., 2003). These factors make inter-assay comparisons complex. Furthermore, no formal external quality assessment schemes for M. pneumoniae serology or molecular detection exist. Such a scheme could provide highly beneficial data regarding the detection of infection with this pathogen.

\section{Specificity}

The assay was found to be highly specific in that DNA extracted from reference cultures (15 human mollicute species and 19 common respiratory bacteria) did not give a positive signal in the assay, even when tested at concentrations significantly higher than the limit of detection. A search of GenBank using the BLAST algorithm (Altschul et al., 1990) revealed no significant homology of the target sequence with any other known genes $(\mathrm{E}$ value $=5 \cdot 8)$. Of the 150 patients where the primary diagnosis was not infection with M. pneumoniae infection, five $(3.3 \%)$ were PCR positive for M. pneumoniae. One had been serologically confirmed as positive for Chlamydophila spp. by complement fixation tests, one as $H$. influenzae positive by isolation from sputum and three as $S$. pneumoniae positive by isolation from sputum or antigen detection. This gives an overall percentage specificity of $96 \cdot 7 \%(5 / 150)$. These results could represent either false-positive reactions with other bacterial DNA, coinfection with $M$. pneumoniae prior to the formation of a detectable serum-antibody response or detection of residual M. pneumoniae DNA from a past infection. The former is unlikely, as none of the DNA from these three pathogens resulted in amplification in the assay. In addition, all five samples had low concentrations of detectable M. pneumoniae DNA ( $<260$ copies per reaction). Low levels of colonization may be detected by PCR prior to a detectable serological response in patients with or without symptoms. Indeed, several specimens from patients that were negative serologically exhibited $\mathrm{Cp}$ values close to the limits of detection ( $<10$ copies per sample). This may represent a technical artefact or could be detection of low levels of infection. Asymptomatic carriage has been reported to occur within the community and up to $13 \%$ of healthy adults may act as carriers of $M$. pneumoniae, particularly during epidemic periods (Gnarpe et al., 1992; Foy, 1993). Interestingly, Principi et al. (2001) detected M. pneumoniae by PCR in $3.8 \%(16 / 419)$ of children without serological evidence of acute infection. Patients positive for M. pneumoniae had a mean age of $37 \cdot 8$ ( $\mathrm{SD} \pm 18 \cdot 3,95 \% \mathrm{CI}$ $29 \cdot 2-46 \cdot 3$, range $18-78$ ), significantly younger than patients in which $M$. pneumoniae was not detected (mean age of $50 \cdot 6, \mathrm{SD} \pm 19 \cdot 1,95 \% \mathrm{CI} 44 \cdot 6-56 \cdot 7$, range $18-80$ ) (Fisher's exact test, $P=0 \cdot 014$ ).

\section{Control of inhibition}

It is essential that respiratory samples inhibitory to realtime PCR are identified to ensure that they are not falsely reported as negative. Single-tube methods that simultaneously detect IPC and target DNA amplicons of differing lengths with the same primers have been used in isothermal amplification and real-time methods for $M$. pneumoniae (Loens et al., 2002; Ursi et al., 2003). We developed a similar IPC consisting of a cloned PCR fragment of the $\lambda$ phage genome flanked by primer sites for the M. pneumoniae PCR. When used with target and $\lambda$-specific probes that fluoresce at different wavelengths, the same set of primers amplifies both M. pneumoniae and IPC, detecting both products simultaneously. Furthermore, the size of the IPC amplicon (278 bp) is larger than that of the target (141 bp) amplicon and the latter reaction is driven preferentially at the expense of the former (Fig. 2). Only when target DNA is low in concentration or absent will any IPC sequence be amplified, and inhibition is detected in reactions with an absence of both target DNA and IPC amplicons. The IPC was stable when $\mathrm{Cp}$ values were monitored over several months with a SD of approximately 1.0 for 10 sets of standards $\left(10^{1}\right.$ copies per reaction: $\mathrm{Cp} 32 \cdot 1-35 \cdot 4$, mean $33 \cdot 5, \mathrm{SD} \pm 1 \cdot 03 ; 10^{2}$ copies per reaction: $\mathrm{Cp} 28 \cdot 8-31 \cdot 3$, mean $30 \cdot 0, \mathrm{SD} \pm 0 \cdot 87 ; 10^{3}$ copies per reaction: $\mathrm{Cp} 24 \cdot 5-27 \cdot 2$, mean $25 \cdot 9, \mathrm{SD} \pm 0 \cdot 99 ; 10^{4}$ copies per reaction: $\mathrm{Cp} 21 \cdot 5-24 \cdot 4$, mean $22 \cdot 4, \mathrm{SD} \pm 0 \cdot 98 ; 10^{5}$ copies per reaction: $\mathrm{Cp} 16 \cdot 1-19 \cdot 8$, mean $17 \cdot 9, \mathrm{SD} \pm 0 \cdot 97)$.

In the current study, 40/167 (24.0\%) of undiluted samples were inhibitory to the assay (note that eight samples were 


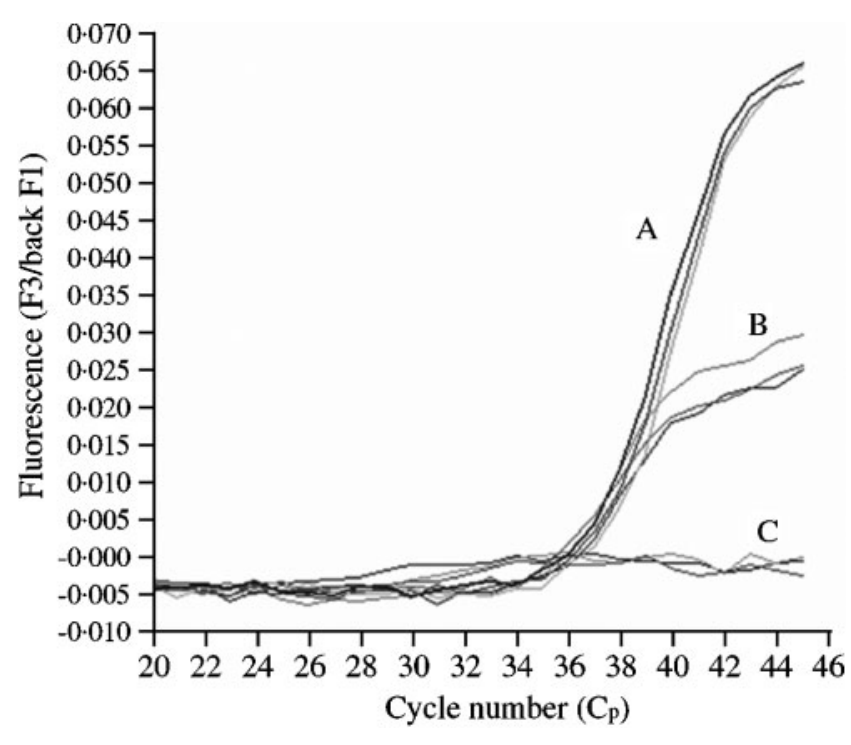

Fig. 2. Internal processing control (IPC) at a concentration of $10^{2}$ copies per PCR in the presence of no target DNA (A), $10^{1}$ copies target DNA (B), or $10^{2}$ copies target DNA (C). Channel F3, Red 705 fluorescence.

only tested at a 1/10 dilution due to limited sample volume). By retesting a 10-fold dilution, this was reduced to $7 / 175$ (4.0\%). These results support those of Dorigo-Zetsma et al. (1999), in which $20 \%$ of throat-swab extracts inhibited amplification for M. pneumoniae and this inhibition was removed by sample dilution. Abele-Horn et al. (1998) reported inhibition in $10 \%$ of samples, which was reduced to $2 \%$ by the use of a 1 day culture enhancement. Raggam et al. (2005) and Stralin et al. (2005) found no inhibition with respiratory samples. Ursi et al. (2003) reported that $2 / 115(1.7 \%)$ respiratory samples were inhibitory. Both sample viscosity (Loens et al., 2002) and the pretreatment of samples with mucolytic agents (dithiothreitol) used to reduce viscosity (Deneer \& Knight, 1994) have been reported to cause false-negative results. In this study, differing extraction methods and the resulting effect on assay performance were not examined. A single method of extraction was employed that is well established in the laboratory for extracting DNA from respiratory specimens (QiAamp DNA Mini kit; Qiagen). Total DNA content may also affect PCR whereby increasing amounts of non-target DNA inhibit amplification of the target DNA. In respiratory specimens, human DNA, as well as DNA from other micro-organisms, may cause inhibition (Ludwig \& Schleifer, 2000).

This study is similar to that by Ursi et al. (2003) in that a real-time assay for the $\mathrm{P} 1$ gene of $M$. pneumoniae with the same primer IPC was employed to compare detection of $M$. pneumoniae in respiratory specimens. Both studies used the same platform, similar methods of DNA extraction and a similar methodology and detected comparable concentrations of M. pneumoniae in respiratory samples (Ursi et al.,
2003: $5 \times 10^{3}-5 \times 10^{10}$ organisms $\mathrm{ml}^{-1}$; this study: $5 \times 10^{3}-$ $6 \times 10^{7}$ organisms $\left.\mathrm{ml}^{-1}\right)$. However, our study examined a larger number of patients (175 compared with 82), improved the limit of detection by at least fivefold $\left(1 \times 10^{3}\right.$ compared with $5 \times 10^{3}-5 \times 10^{4}$ organisms $\mathrm{ml}^{-1}$ ) and was tested against a comprehensive panel of human Mycoplasma species and respiratory pathogens. Another important difference to note is that this study compared real-time PCR with serologically positive patients (and some that were culture-positive), whereas Ursi et al. (2003) compared the real-time assay with isothermal PCR using exactly the same target. Ursi et al. (2003) recommended testing lower respiratory tract specimens rather than upper respiratory tract specimens for M. pneumoniae due to the higher concentrations of detectable M. pneumoniae DNA. Here, lower respiratory tract samples from patients with clinically defined pneumonia that had been screened previously for a large panel of respiratory pathogens were tested. This may account for the difference noted in the number of inhibitory samples: Ursi et al. (2003) tested throat swabs, throat washings and sputa, with $2 / 115(1.7 \%)$ showing inhibition that was eliminated by sample dilution. This study comprised lower respiratory tract samples only, of which $24 \%$ were inhibitory; this was reduced to $4 \%$ by dilution. We therefore recommend testing of all lower respiratory tract DNA samples undiluted and at a 1/10 dilution for M. pneumoniae detection.

\section{Conclusions}

This assay for detecting M. pneumoniae in the respiratory tract is reproducible, with a sensitivity of $60.0 \%$ in comparison with serology and a specificity of $96 \cdot 7 \%$. The method is rapid and up to 27 extracted samples can be assayed in less than an hour, ideal for same-day screening of patients with respiratory symptoms. The use of a coamplified IPC in the same tube and employing the same primers as the target sample increases the throughput of specimens for diagnosis and reduces cost. The use of undiluted and 1/10 dilutions of specimens decreased the observed inhibition from 24 to $4 \%$. Validation of extraction methods to resolve sample inhibition would be beneficial, but would require large volumes of clinical specimens. Dual infections were found in five $(3.3 \%)$ of the samples tested, and overall 20/175 (11.4\%) samples were PCR positive for $M$. pneumoniae. This study included validation of the assay on respiratory specimens that are highly defined for other respiratory infections, but was limited by the absence of control specimens from healthy individuals and the age of the specimens under test. It is difficult to gain access to respiratory specimens that have been tested for a full range of respiratory specimens with relevant clinical and matching serological data. Such a collection could be invaluable for assay comparison to ensure the best patient service as new techniques for M. pneumoniae and other fastidious respiratory pathogens are described. 


\section{ACKNOWLEDGEMENTS}

The authors would like to thank Dr Margaret Sillis for advice and the provision of some specimens and Andrew Grant and Tom Nichols for statistical assistance.

\section{REFERENCES}

Abele-Horn, M., Busch, U., Nitschko, H., Jacobs, E., Bax, R., Pfaff, F., Schaffer, B. \& Heesemann, J. (1998). Molecular approaches to diagnosis of pulmonary diseases due to Mycoplasma pneumoniae. J Clin Microbiol 36, 548-551.

Altschul, S. F., Gish, W., Miller, W., Myers, E. W. \& Lipman, D. J. (1990). Basic local alignment search tool. J Mol Biol 215, 403-410.

Cloud, J. L., Hymas, W. C., Turlak, A., Croft, A., Reischl, U., Daly, J. A. \& Carroll, K. C. (2003). Description of a multiplex Bordetella pertussis and Bordetella parapertussis LightCycler ${ }^{\circledR}$ PCR assay with inhibition control. Diagn Microbiol Infect Dis 46, 189-195.

Clyde, W. A., Jr (1993). Clinical overview of typical Mycoplasma pneumoniae infections. Clin Infect Dis 17 (Suppl. 1), S32-S36.

Deneer, H. G. \& Knight, I. (1994). Inhibition of the polymerase chain reaction by mucolytic agents. Clin Chem 40, 171-172.

Dorigo-Zetsma, J. W., Zaat, S. A. J., Wertheim-van Dillen, P. M. E., Spanjaard, L., Rijntjes, J., van Waveren, G., Jensen, J. S., Angulo, A. F. \& Dankert, J. (1999). Comparison of PCR, culture and serological tests for diagnosis of Mycoplasma pneumoniae respiratory tract infection in children. J Clin Microbiol 37, 14-17.

Foy, H. M. (1993). Infections caused by Mycoplasma pneumoniae and possible carrier state in different populations of patients. Clin Infect Dis 17 (Suppl. 1), S37-S46.

Friedlaender, R. P., Grizzard, M. B., Helms, C. M., Barile, M. F., Senterfit, L. \& Chanock, R. M. (1976). Experimental production of respiratory tract infection with Mycoplasma pneumoniae in rhesus monkeys. J Infect Dis 133, 343-346.

Gnarpe, J., Lundback, A., Sundelof, B. \& Gnarpe, H. (1992). Prevalence of Mycoplasma pneumoniae in subjectively healthy individuals. Scand J Infect Dis 24, 161-164.

Hardegger, D., Nadal, D., Bossart, W., Altwegg, M. \& Dutly, F. (2000). Rapid detection of Mycoplasma pneumoniae in clinical samples by real-time PCR. J Microbiol Methods 41, 45-51.

levens, M., Ursi, D., van Bever, H., Quint, W., Niesters, H. G. M. \& Goossens, H. (1996). Detection of Mycoplasma pneumoniae by two polymerase chain reactions and role of $M$. pneumoniae in acute respiratory tract infections in pediatric patients. J Infect Dis 173, 1445-1452.

Khanna, M., Fan, J., Pehler-Harrington, K., Waters, C., Douglass, P., Stallock, J., Kehl, S. \& Henrickson, K. J. (2005). The pneumoplex assays, a multiplex PCR-enzyme hybridization assay that allows simultaneous detection of five organisms, Mycoplasma pneumoniae, Chlamydia (Chlamydophila) pneumoniae, Legionella pneumophila, Legionella micdadei, and Bordetella pertussis, and its real-time counterpart. J Clin Microbiol 43, 565-571.

Loens, K., Ursi, D., leven, M., van Aarle, P., Sillekens, P., Oudshoorn, P. \& Goosens, H. (2002). Detection of Mycoplasma pneumoniae in spiked clinical samples by nucleic acid sequencebased amplification. J Clin Microbiol 40, 1339-1345.

Loens, K., Ursi, D., Goossens, H. \& Leven, M. (2003). Molecular diagnosis of Mycoplasma pneumoniae respiratory tract infections. J Clin Microbiol 41, 4915-4923.
Longo, M. C., Berninger, M. S. \& Hartley, J. L. (1990). Use of uracil DNA glycosylate to control carry-over in polymerase chain reaction. Gene 93, 125-128.

Ludwig, W. \& Schleifer, K.-H. (2000). How quantitative is quantitative PCR with respect to cell counts? Syst Appl Microbiol 23, $556-562$.

McMillan, J. A. (1998). Mycoplasma pneumoniae infection in pediatrics. Semin Pediatr Infect Dis 9, 112-119.

Michelow, I. C., Olsen, K., Lozano, J., Duffy, L. B., McCracken, G. H. \& Hardy, R. D. (2004). Diagnostic utility and clinical significance of naso- and oropharyngeal samples used in a PCR assay to diagnose Mycoplasma pneumoniae infection in children with communityacquired pneumonia. J Clin Microbiol 42, 3339-3341.

Miyashita, N., Saito, A., Kohno, S., Yamaguchi, K., Watanabe, A., Oda, H., Kazuyama, Y., Matsushima, T. \& the CAP Study Group (2004). Multiplex PCR for the simultaneous detection of Chlamydia pneumoniae, Mycoplasma pneumoniae and Legionella pneumophila in community-acquired pneumonia. CAP Study Group. Respir Med 98, $542-550$.

Mygind, T., Birkelund, S., Falk, E. \& Christiansen, G. (2001). Evaluation of real-time quantitative PCR for identification and quantification of Chlamydia pneumoniae by comparison with immunohistochemistry. J Microbiol Methods 46, 241-251.

Nour, M., Trabelsi, A., Maatouk, N. \& Hammami, M. (2005). Amplification of P1 and 16S rRNA genes by nested PCR for detection of Mycoplasma pneumoniae in paediatric patients. Pathol Biol (Paris) 53, 9-14.

Principi, N., Esposito, S., Blasi, F., Allegra, L. \& the Mowgli Study Group (2001). Role of Mycoplasma pneumoniae and Chlamydia pneumoniae in children with community-acquired lower respiratory tract infections. Clin Infect Dis 32, 1281-1289.

Raggam, R. B., Leitner, E., Berg, J., Mühlbauer, G., Marth, E. \& Kessler, H. H. (2005). Single-run, parallel detection of DNA from three pneumonia-producing bacteria by real-time polymerase chain reaction. J Mol Diagn 7, 133-138.

Razin, S. (1994). DNA probes and PCR in diagnosis of mycoplasma infections. Mol Cell Probes 8, 497-511.

Sillis, M. (1993). Modern methods for diagnosis of Mycoplasma pneumoniae. Rev Med Microbiol 4, 24-31.

Stralin, K., Backman, A., Holmberg, H., Fredlund, H. \& Olcen, P. (2005). Design of a multiplex PCR for Streptococcus pneumoniae, Haemophilus influenzae, Mycoplasma pneumoniae and Chlamydophila pneumoniae to be used on sputum samples. APMIS 113, 99-111.

Su, C. J., Tryon, V. V. \& Baseman, J. B. (1987). Cloning and sequence analysis of cytadhesin P1 gene from Mycoplasma pneumoniae. Infect Immun 55, 3023-3029.

Svenstrup, H. F., Nielsen, P. K., Drasbek, M., Birkelund, S. \& Christiansen, G. (2002). Adhesion and inhibition assay of Mycoplasma genitalium and M. pneumoniae by immunofluorescence microscopy. J Med Microbiol 51, 361-373.

Ursi, D., Dirven, K., Loens, K., leven, M. \& Goossens, H. (2003). Detection of Mycoplasma pneumoniae in respiratory samples by real-time PCR using an inhibition control. J Microbiol Methods 55, 149-153.

Whiley, D. M., LeCornec, G. M., Mackay, I. M., Siebert, D. J. \& Sloots, T. P. (2002). A real-time PCR assay for the detection of Neisseria gonorrhoeae by LightCycler. Diagn Microbiol Infect Dis 42, 85-89.

Wreghitt, T. G. \& Sillis, M. (1985). A micro-capture ELISA for detecting Mycoplasma pneumoniae IgM: comparison with indirect immunofluorescence and indirect ELISA. J Hyg 94, 217-227. 